\title{
Ventilatory control in patients with sleep apnoea and left ventricular dysfunction: comparison of obstructive and central sleep apnoea
}

\author{
I. Wilcox*+\#, S.G. McNamara*\#, M.J. Dodd\#, C.E. Sullivan*\#
}

Ventilatory control in patients with sleep apnoea and left ventricular dysfunction: comparison of obstructive and central sleep apnoea. I. Wilcox, S.G. McNamara, M.J. Dodd, C.E. Sullivan. OERS Journals Ltd 1998.

ABSTRACT: Sleep apnoea is common in patients with heart failure. While most patients have central sleep apnoea (CSA), a minority have obstructive sleep apnoea (OSA). The pathophysiology of CSA is not well understood. We hypothesized that central chemosensitivity would be an important pathophysiological factor in patients with CSA, and not in OSA. The aim of this study was to compare ventilatory responses between patients with CSA and those with OSA.

Acute ventilatory responses to eucapnic hypoxia and hyperoxic hypercapnia were measured during wakefulness in 34 patients (33 males and one female, aged $59 \pm 8$ yrs $($ mean \pm sD) $)$, with stable medically-treated left ventricular dysfunction (LVD) and sleep apnoea (18 OSA and 16 CSA).

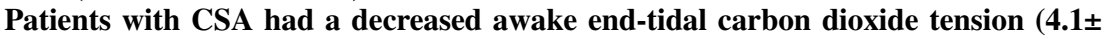
$0.5 \mathrm{kPa})$, increased ventilatory response to carbon dioxide $\left(0.65 \pm 0.43 \mathrm{~L} \cdot \mathrm{min}^{-1} \cdot \mathrm{kPa}\right.$ $\left.\mathrm{PCO}_{2}{ }^{-1}\right)$, and eucapnic hypoxic responses in the normal range $(0.6 \pm 0.4 \mathrm{~L} \cdot \mathrm{min} \cdot 1 / \%$ fall in arterial oxygen saturation $\left.\left(\mathrm{Sa}, \mathrm{O}_{2}\right)\right)$. In contrast, patients with OSA had normal endtidal carbon dioxide tension $(4.9 \pm 0.5 \mathrm{kPa})$, and normal ventilatory responses to hypercapnia $\left(0.29 \pm 0.16 \mathrm{~L} \cdot \mathrm{min}^{-1} \cdot \mathrm{kPa} P \mathrm{PO}_{2}{ }^{-1}\right)$ and hypoxia $\left(0.5 \pm 0.5 \mathrm{~L} \cdot \mathrm{min}^{-1 / \%}\right.$ fall in $\left.\mathrm{Sa}, \mathrm{O}_{2}\right)$.

These findings suggest that augmented chemosensitivity to hypercapnia may be an important factor in the pathophysiology of central sleep apnoea in patients with heart failure.

Eur Respir J 1998; 11: 7-13.
*David Read Laboratory, Dept of Medicine, University of Sydney, Sydney, Australia. ${ }^{+}$Dept of Cardiology and ${ }^{\#}$ Centre for Respiratory Failure and Sleep Disorders, Royal Prince Alfred Hospital, Sydney, Australia.

Correspondence: I. Wilcox

David Read Laboratory

Dept of Medicine (DO6)

University of Sydney

NSW 2006

Australia

Fax: 0061295194938

Keywords: Cardiac failure

central sleep apnoea

chemoreceptors

obstructive sleep apnoea

ventilatory responses

Received: January 141997

Accepted after revision July 301997

Supported by a Project Grant from the National Health and Medical Research Council of Australia.
It is well known that abnormal breathing during wakefulness (periodic or Cheyne-Stokes respiration) occurs in patients with severe heart failure $[1,2]$. This breathing abnormality, characterized by alternating periods of hyperpnoea and hypopnoea or apnoea, is one form of central apnoea and appears to be much more common during sleep (central sleep apnoea (CSA)) than wakefulness [3]. The main mechanism responsible for Cheyne-Stokes respiration is believed to be a phase delay between peripheral and central chemoreceptors due to prolonged circulation time [4]. This phase delay would promote unstable respiratory control, leading to periodic respiration with alternating hyperpnoea and hypopnoea or apnoeas.

Unstable respiratory control is more likely to occur during sleep because of the influence of the sleep-wake state on respiratory control. During wakefulness, chemical and other influences on breathing are relatively less important than during sleep, when breathing is markedly influenced by stimuli such as hypoxia, hypercapnia and acid-base status [5]. Hypocapnia during wakefulness has little effect on respiration, whereas hypocapnia during sleep may lead to central apnoea at a threshold value (apnoea threshold) which may be only slightly less than normal awake values of carbon dioxide tension $\mathrm{PCO}_{2}$ [6]. Thus, unstable respiratory control is more likely to be evi-

For editorial comment see page 3-4 dent during sleep, and increased gain in the central chemoreceptors is likely to promote CSA.

CSA is a heterogeneous and relatively rare condition in adults without heart disease. A subset of patients with central apnoea have hypocapnia during wakefulness and normal or increased ventilatory responses to hypercapnia [7]. NAUGHTON et al. [8] recently studied a group of patients with CSA and heart failure, noting that this group of patients had hypocapnia during sleep and wakefulness compared to controls with heart failure and no CSA. The factor(s) responsible for hypocapnia in these patients were not identified in the study. In a prelimi- nary study, we have shown that patients with congestive heart failure and CSA have higher than normal ventila-tory responses to hypercapnia [9], but others have not confirmed this finding [10]. ChuA et al. [11] did report increased ventilatory responses both to hypoxia and hy-percapnia in patients with heart failure, but their patients were not reported to have sleep apnoea. If increased sen-sitivity of central chemoreceptors is an important deter-minant of central apnoea in heart failure, hypercapnic ventilatory responses should be increased in patients with predominantly CSA and relatively normal in patients with obstructive sleep apnoea (OSA).

The aim of this study was to examine daytime ventilatory control in patients with a clinical sleep disorder and 
left ventricular dysfunction (LVD), and to compare hypoxic and hypercapnic responses between patients with predominantly CSA and those with obstructive apnoea.

\section{Methods}

\section{Patient selection}

We selected consecutive patients referred to our sleep disorders centre with symptoms of sleep-disordered breathing (sleep fragmentation, with or without repetitive snoring, witnessed apnoeas, excessive daytime sleepiness) and left ventricular systolic dysfunction (left ventricular ejection fraction $(\mathrm{LVEF})<50 \%$ ). Patients with respiratory failure, known cerebrovascular disease and other noncardiac causes of CSA, or continuing high alcohol intake $\left(>80 \mathrm{~g} \cdot \mathrm{day}^{-1}\right)$, were excluded. Patients included were not matched for baseline clinical characteristics, apnoea severity or apnoea type (either OSA or CSA). The study was approved by our institution's Ethics Committee and informed consent was obtained from all patients.

\section{Sleep studies}

Sleep studies were performed between 22:00 and 06:00 h. Parameters monitored and recorded included: electroencephalogram (EEG) (C4/A1, O2/A1); electro-oculogram; submental electromyogram (EMG); and diaphragmatic EMG. Airflow was measured at the nares using nasal prongs connected to a differential pressure transducer (PT 5; Grass Instruments, Quincy, MA, USA). Respiratory movement was measured using chest and abdominal strain gauge transducers (Respitrace, Ambulatory Monitoring, Ardsley, New York, NY, USA). Arterial oxygen saturation $\left(\mathrm{Sa}_{\mathrm{a}} \mathrm{O}_{2}\right)$ was measured using a pulse oximeter with an ear probe (Biox 3700E; Ohmeda, Englewood, CO, USA). All data were recorded either on a polygraph recorder (Model 78D; Grass Instruments, Quincy, MA, USA) or a computerized sleep analysis system (Sleepwatch ${ }^{\mathrm{TM}}$; Compumedics, Vic, Australia). Sleep staging was performed according to standard criteria [12]. An apnoea was defined as $10 \mathrm{~s}$ or more of complete absence of airflow, and a hypopnoea was defined as a reduction in airflow signal of greater than $50 \%$ for a period of $\geq 10 \mathrm{~s}$. Respiratory events were classified as obstructive if there were continued respiratory efforts during the apnoea (indicated by chest or abdominal movement), or central if there were no respiratory efforts during the apnoea or hypopnoea. Obstructive sleep apnoea was considered present if a mean of more than 10 obstructive apnoeas or hypopnoeas per hour (apnoea/hypopnoea index (AHI)) of sleep were detected. Similarly, CSA was diagnosed if a mean of more than 10 central apnoeas or hypopnoeas $\cdot \mathrm{h}^{-1}$ of sleep were present. Sleep-disordered breathing was classified as either predominantly central, obstructive or mixed (obstructive and central apnoea) apnoea by a physician (MJD), who was blinded to the patients' clinical and ventilatory response data. An arbitrary cut-off of greater than $75 \%$ of respiratory events was used to classify each patient's apnoea as either central or obstructive. Patients with both central and obstructive apnoea ("mixed apnoea") were not included in the study.

\section{Ventilatory response testing}

Ventilatory responses were measured on the morning following overnight polysomnography using a computercontrolled rebreathing circuit, described in detail previously [13]. Patients remained fasted and were seated upright during testing.

Patients were connected via a mouthpiece to the rebreathing circuit. A fixed speed blower-motor provided a constant bias-flow throughout the circuit. Airflow was measured with a pneumotachograph and differential pressure transducer (DP-45; Validyne Corp., Northridge, CA, USA) and digitized at $125 \mathrm{~Hz}$ (RTI 815A; Analog Devices Inc., Norwood, MA, USA). Tidal volume was calculated by digitally integrating the airflow signal and breath-by-breath minute ventilation $\left(V^{\prime} \mathrm{E}\right)$ was calculated. End-tidal $\mathrm{CO}_{2}$ tension $\left(P\right.$ ET, $\left.\mathrm{CO}_{2}\right)$ was measured using an infra-red carbon dioxide analyser (Hewlett-Packard 47210A; Waltham, MA, USA) attached to the mouthpiece. Oxyhaemoglobin saturation $\left(\mathrm{Sa}_{\mathrm{a}} \mathrm{O}_{2}\right)$ was measured via an ear probe (Ohmeda 3700e; Boulder, CO, USA). To follow the protocol set by the operator, computer software controlled the addition of $\mathrm{O}_{2}, \mathrm{CO}_{2}$, nitrogen and room air to the circuit, as well as varying the proportion of airflow through one limb of the apparatus, which included a soda-lime absorber.

Ventilatory responses to hyperoxic hypercapnia. The hypercapnic ventilatory response (HCVR) was measured using a modification of the READ [14] rebreathing technique. The subject breathed a $\mathrm{CO}_{2}-\mathrm{O}_{2}$ gas mixture, with an initial $\mathrm{CO}_{2}$ concentration chosen to rapidly produce a plateau in $P$ ET, $\mathrm{CO}_{2}$, with a subsequent increase in carbon dioxide tension at a linear rate of approximately $0.8 \mathrm{kPa} \cdot \mathrm{min}^{-1}$. The test was terminated at maximum tolerated ventilation, typically within $2 \mathrm{~min}$. $P \mathrm{ET}, \mathrm{CO}_{2}$ and $V^{\prime} \mathrm{E}\left(\mathrm{L} \cdot \mathrm{min}^{-1}\right)$ were analysed on-line. The ventilatory response to $\mathrm{CO}_{2}$ was expressed as the slope of the regression line of $V^{\prime} \mathrm{E}$ on $P \mathrm{ET}, \mathrm{CO}_{2}$. Normal values for the HCVR in our laboratory are less than $0.43 \mathrm{~L} \cdot \mathrm{min}^{-1} \cdot \mathrm{kPa} P \mathrm{CO}_{2}^{-1}$.

Ventilatory responses to eucapnic hypoxia. The ventilatory response to acute eucapnic hypoxia was measured using the method of ReBucK and CAMPBELL [15]. After a period of stabilization breathing room air on the circuit, baseline $P$ ET, $\mathrm{CO}_{2}$ was measured. Airflow to the circuit was then stopped and $100 \% \mathrm{~N}_{2}$ added in a controlled fashion. $P$ ET, $\mathrm{CO}_{2}$ was constantly maintained at the patient's baseline $P$ ET, $\mathrm{CO}_{2}$ by computer-controlled adjustment of the proportion of expired gas passed through a soda-lime $\mathrm{CO}_{2}$ absorber. The test was terminated at an $\mathrm{Sa}_{\mathrm{a}} \mathrm{O}_{2}$ of $70 \%$ or at the maximum tolerated ventilation, typically after 2-3 min. $P$ ET, $\mathrm{CO}_{2}$, transcutaneous $S \mathrm{a}, \mathrm{O}_{2}$ and $V^{\prime} \mathrm{E}$ were analysed on-line. The ventilatory response to hypoxia was expressed as the slope of the regression line of $V^{\prime} \mathrm{E}$ on $\mathrm{Sa}, \mathrm{O}_{2}$ $\left(\mathrm{L} \cdot \mathrm{min}^{-1 / \%} \quad \mathrm{Sa}_{\mathrm{a}} \mathrm{O}_{2}\right)$. The normal range for the eucapnic hypoxic response in our laboratory is $0.7 \pm 0.2 \mathrm{~L} \cdot \mathrm{min}^{-1 / \%}$ fall in $S a, O_{2}[13,16]$.

\section{Assessment of left ventricular function}

Left ventricular function was measured using radionuclide scintigraphy. Red blood cells were labelled in vivo with stannous pertechnetate and approximately $740 \mathrm{mBq}$ of technetium-99m. Approximately 2 million counts were 
acquired in the left anterior oblique view in the supine position. Analysis was performed using a commercial software package. All studies were interpreted by a nuclear physician blinded to the patients sleep study and ventilatory response data.

\section{Statistical analysis}

All values are expressed as mean \pm SD unless otherwise stated. Statistical analysis was performed using a software package (SPIDA; Statistical Laboratory, Macquarie University, NSW, Australia). Univariate analysis was performed using analysis of variance (ANOVA) or linear regression as appropriate. Before ventilatory response data for each group were compared statistically, a variance ratio test was performed to determine any unequal variance between the group data. If unequal variance was present, a t-test assuming unequal variance was used for statistical comparison. A two-tailed p-value of less than 0.05 was considered significant; $p$-values less than 0.1 are shown, and p-values greater than 0.1 are shown as nonsignificant (NS).

\section{Results}

The study included 33 males and one female, mean age $59 \pm 9$ yrs (range $43-81 \mathrm{yrs}$ ), mean body mass index (BMI) $30 \pm 6 \mathrm{~kg} \cdot \mathrm{m}^{-2}$ (range $20-44 \mathrm{~kg} \cdot \mathrm{m}^{-2}$ ). All had LVD (radionuclide LVEF $<50 \%$ ), with a mean ejection fraction of $26 \pm$ $8 \%$ (range $13-49 \%$ ), on the basis of either coronary disease (14 patients; $41 \%$ ), dilated cardiomyopathy (18 patients; $53 \%$ ) or valvular heart disease (2 patients; $6 \%$ ). The majority of the patients were symptomatic, with dyspnoea on exertion. Four patients $(12 \%)$ were New York Heart Association (NYHA) class I, seven patients (20\%) NYHA class II, 16 patients $(47 \%)$ class III, and seven patients (21\%) class IV. All except one patient were on standard heart failure therapy, including digoxin (27 patients; $79 \%$ ), diuretics (28 patients; 82\%), and angiotensin converting enzyme (ACE) inhibitors (33 patients; 97\%).

All patients had sleep-disordered breathing with an AHI $>10$ events $\cdot h^{-1}$, including 16 patients with CSA and 18 patients (including the one female) with OSA. The mean AHI was $41 \pm 19$ events $\cdot \mathrm{h}^{-1}$ (range $12-86$ events $\cdot \mathrm{h}^{-1}$ ) and mean minimum $\mathrm{Sa}_{\mathrm{a}} \mathrm{O}_{2}$ was $75 \pm 11 \%$ (range 36-90\%) during sleep. Resting $P$ ET, $\mathrm{CO}_{2}$, measured in the sitting position, was $4.7 \pm 0.7 \mathrm{kPa}$ (range $3.3-6.0 \mathrm{kPa}$ ). The ventilatory responses to eucapnic hypoxia were within the normal laboratory range, measuring $0.6 \pm 0.4$ (range $0.1-$ 1.6) $\mathrm{L} \cdot \mathrm{min}^{-1} / \%$ fall in $\mathrm{Sa}, \mathrm{O}_{2}$, while the HCVRs were mildly increased at $0.47 \pm 0.36$ (range $0.01-1.33$ ) L. $\mathrm{min}^{-1} / \mathrm{kPa}$ increase in $\mathrm{PCO}_{2}$. Ventilatory responses to hypoxia were not measured in seven patients who had either severe angina or known high grade cardiac arrhythmias. Five of these patients had central sleep apnoea and two had OSA. None of the patients tested experienced any adverse events during ventilatory response testing.

There were significant differences in baseline variables between the two patient groups, as shown in table 1 . Patients with CSA were older, less obese, and had more severe LVD. Although the severity of sleep-disordered breathing, based on AHI, was similar in patients with CSA $\left(41 \pm 11\right.$ events $\left.\cdot \mathrm{h}^{-1}\right)$ and those with OSA $(41 \pm 25$
Table 1. - Comparison of clinical, polysomnographic and ventilatory response data between patients with central and obstructive sleep apnoea

\begin{tabular}{|c|c|c|c|}
\hline & CSA & OSA & $\mathrm{p}$-value \\
\hline Age yrs & $65 \pm 8$ & $55 \pm 7$ & $<0.001$ \\
\hline Body mass index $\mathrm{kg} \cdot \mathrm{m}^{-2}$ & $26 \pm 4$ & $33 \pm 5$ & $<0.001$ \\
\hline LVEF \% & $23 \pm 9$ & $29 \pm 6$ & 0.025 \\
\hline \multicolumn{4}{|l|}{ Sleep architecture } \\
\hline NREM \% & $66 \pm 14$ & $70 \pm 8$ & NS \\
\hline REM \% & $11 \pm 8$ & $11 \pm 6$ & NS \\
\hline AHI overall events $\cdot \mathrm{h}^{-1}$ & $41 \pm 11$ & $41 \pm 25$ & NS \\
\hline NREM AHI event $\cdot h^{-1}$ & $40 \pm 12$ & $42 \pm 28$ & NS \\
\hline REM AHI events.h-1 & $39 \pm 12$ & $35 \pm 22$ & NS \\
\hline Awake $\mathrm{Sa}_{\mathrm{a}} \mathrm{O}_{2} \%$ & $95 \pm 2$ & $94 \pm 2$ & NS \\
\hline Mean minimum $\mathrm{Sa}_{\mathrm{a}, \mathrm{O}_{2}} \%$ & $79 \pm 7$ & $72 \pm 13$ & NS \\
\hline$P \mathrm{ET}, \mathrm{CO}_{2} \mathrm{kPa}$ & $4.1 \pm 0.5$ & $4.9 \pm 0.5$ & $<0.001$ \\
\hline $\begin{array}{l}\mathrm{CO}_{2} \text { response } \\
\mathrm{L} \cdot \mathrm{min}^{-1} \cdot \mathrm{kPa} \mathrm{PCO}_{2}^{-1}\end{array}$ & $0.65 \pm 0.43$ & $0.29 \pm 0.16$ & 0.005 \\
\hline $\begin{array}{l}\text { Hypoxic response } \\
\mathrm{L} \cdot \min ^{-1} . \% \mathrm{Sa}_{\mathrm{a}} \mathrm{O}_{2}\end{array}$ & $0.6 \pm 0.4$ & $0.5 \pm 0.5$ & NS \\
\hline
\end{tabular}

CSA: central sleep apnoea; OSA: obstructive sleep apnoea; LVEF: left ventricular ejection fraction; NREM: non-rapid eye movement; REM: rapid eye movement; $\mathrm{Sa}_{2} \mathrm{O}_{2}$ : arterial oxygen saturation; $P \mathrm{ET}, \mathrm{CO}_{2}$ : end-tidal carbon dioxide tension; $\mathrm{PCO}_{2}$ : carbon dioxide tension. ns: nonsignificant; AHI: apnoea/hypopnoea index.

events $\cdot \mathrm{h}^{-1} ; \mathrm{p}=\mathrm{NS}$ ), there was a nonsignificant trend to slightly less severe oxygen desaturation in patients with CSA $(79 \pm 7 \%)$ compared to those with OSA $(72 \pm 13 \%$; $\mathrm{p}=$ 0.10 ). Within the CSA group, although the AHI was lower in rapid eye movement (REM) than non-rapid eye movement (NREM) sleep, this difference was not statistically significant $\left(40 \pm 12\right.$ events $\cdot h^{-1}$ in NREM versus $39 \pm$ 12 events $\cdot h^{-1}$ in REM). Similarly, in the OSA group, there was no significant difference in the mean AHI in REM and NREM sleep (42 \pm 28 events $\cdot \mathrm{h}^{-1}$ in NREM versus $35 \pm$ 22 events $\cdot h^{-1}$ in REM)

Patients with CSA had markedly increased HCVRs $\left(0.65 \pm 0.43 \mathrm{~L} \cdot \mathrm{min}^{-1} \cdot \mathrm{kPa} \mathrm{PCO}_{2}^{-1}\right)$, whereas patients with OSA had normal hypercapnic responses $\left(0.29 \pm 0.16 \mathrm{~L} \cdot \mathrm{min}^{-1} \cdot \mathrm{kPa}\right.$ $\left.\mathrm{PCO}_{2}{ }^{-1}\right)$. A variance ratio test showed the variance of the HCVRs between the two groups to be unequal, but the difference in the mean values remained statistically significant even when this was taken into account ( $p=0.005$; fig. 1).

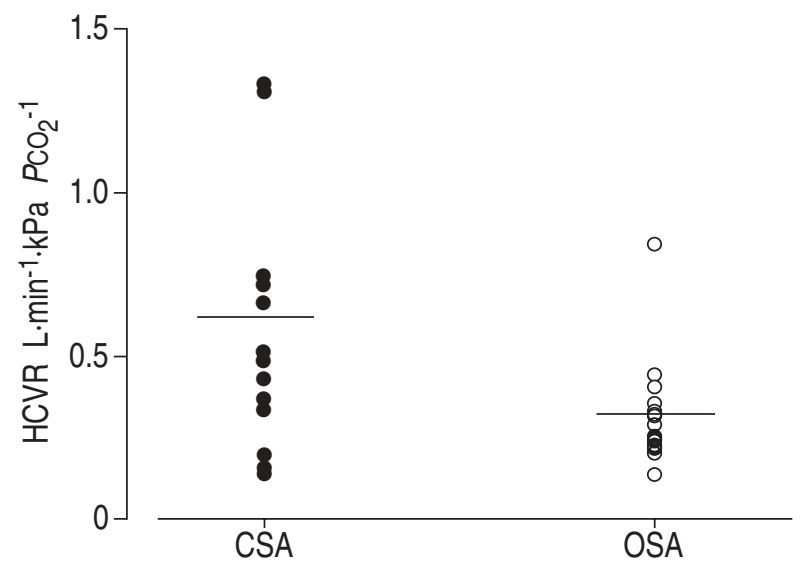

Fig. 1. - Comparison of hypercapnic ventilatory responses between patients with obstructive and central sleep apnoea. Horizontal bars indicate group mean value. CSA: central sleep apnoea; OSA: obstructive sleep apnoea; HCVR: hypercapnic ventilatory response; $\mathrm{PCO}_{2}$ : carbon dioxide tension. 


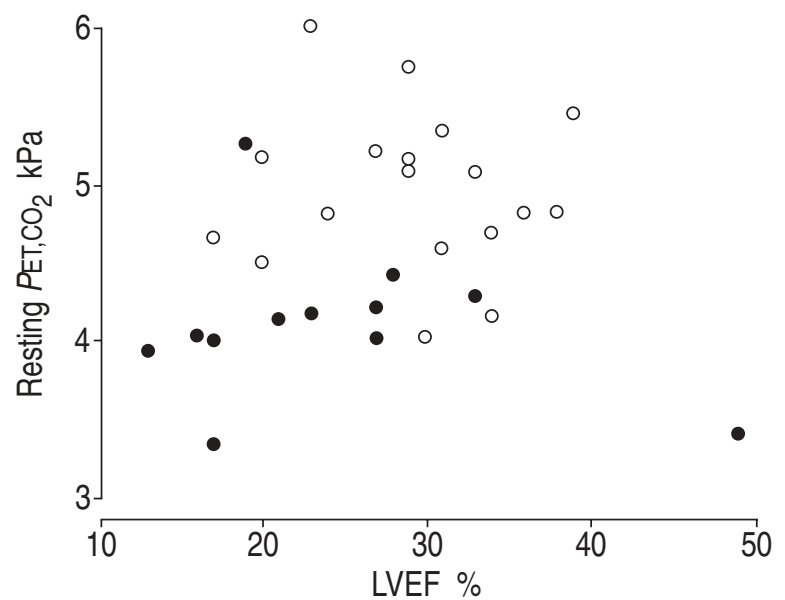

Fig. 2. - Relationship between left ventricular ejection fraction (LVEF) and resting end-tidal $\mathrm{CO}_{2}$ tension $\left(P \mathrm{ET}, \mathrm{CO}_{2}\right)$. $\mathrm{O}$ : obstructive sleep apnoea; $\bullet$ : central sleep apnoea.

One female subject had been included in the OSA group; because of the known difference in HCVRs in females [17], data were also analysed with this subject excluded. Mean group HCVR did not change significantly with the exclusion of the female subject with OSA $(0.32 \pm 0.17$ $\left.\mathrm{L} \cdot \mathrm{min}^{-1} \cdot \mathrm{kPa} \mathrm{PCO}_{2}^{-1}\right)$, and the difference between the OSA and CSA groups remained highly statistically significant. The ventilatory response to eucapnic hypoxia was normal and similar in patients with CSA $\left(0.6 \pm 0.4 \mathrm{~L} \cdot \mathrm{min}^{-1} / \%\right.$ fall in $\left.\mathrm{Sa}, \mathrm{O}_{2}\right)$ and OSA $\left(0.5 \pm 0.5 \mathrm{~L} \cdot \mathrm{min}^{-1 / \%}\right.$ fall in $\mathrm{Sa}_{\mathrm{a}} \mathrm{O}_{2} ; \mathrm{p}=$ NS).

There appeared to be a trend towards higher ventilatory responses to hypercapnia in patients with more severe LVD ( $\mathrm{r}=0.32 ; \mathrm{p}=0.07$ ) (fig. 2), but this was not significant when patients with OSA $(\mathrm{r}=0.10 ; \mathrm{p}=0.8)$ and CSA $(\mathrm{r}=0.22 ; \mathrm{p}=0.4)$ were examined separately. There was no relationship between the degree of impairment of left ventricular function and resting $P$ ET, $\mathrm{CO}_{2}$ while awake $(\mathrm{r}=$ 0.07; p=Ns) (fig. 3). Similarly, there was no relationship between severity of LVD and the ventilatory response to hypercapnia in patients with OSA $(\mathrm{r}=0.25$; $\mathrm{p}=\mathrm{NS})$ or CSA $(\mathrm{r}=0.33 ; \mathrm{p}=\mathrm{NS})$. Ventilatory responses to eucapnic hypoxia did not correlate with the degree of LVD ( $\mathrm{r}=0.19$; $\mathrm{p}=\mathrm{NS})$.

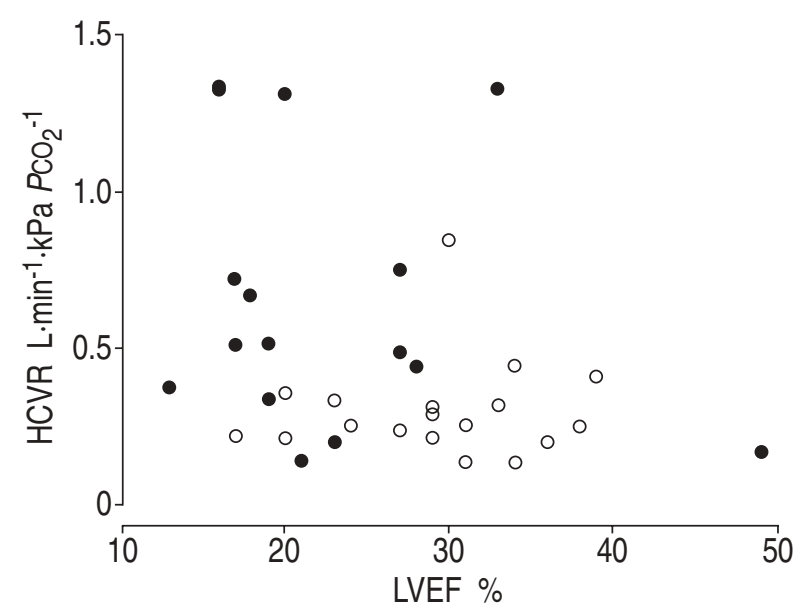

Fig. 3. - Relationship between left ventricular ejection fraction (LVEF) and hypercapnic ventilatory response (HCVR). $\mathrm{PCO}_{2}$ : carbon dioxide tension. $\circ$ : obstructive sleep apnoea; $\bullet$ : central sleep apnoea.

\section{Discussion}

Sleep apnoea has been reported to occur commonly in patients with heart failure [16]. The clinical presentation of sleep apnoea in patients with LVD appears to differ between patients with OSA and those with CSA. The patients included in this study presented with a clinical sleep disorder; those with OSA confirmed by overnight polysomnography were younger, more obese, had better resting left ventricular function and appeared to show a trend towards dilated cardiomyopathy as the underlying cause of their heart failure. The severity of sleep apnoea, based on AHI, was similar, but these important differences in baseline variables suggest that these are two quite separate syndromes. Sleep-disordered breathing in patients with CSA appears to be a consequence of heart failure, whereas in OSA the sleep disorder appears to either cause or at least exacerbate the patient's heart failure [18].

Important differences in ventilatory control were demonstrated between patients with CSA and OSA. Patients with CSA had increased ventilatory responsiveness to hyperoxic hypercapnia. In contrast, patients with OSA and heart failure had hypercapnic ventilatory responses within the range reported for normals [19]. There were no differences in the ventilatory responses to hypoxia when tested at the patients' eucapnic level. The mean levels of these responses were similar $\left(0.6 \mathrm{~L} \cdot \mathrm{min}^{-1} / \%\right.$ fall in $\mathrm{Sa}_{\mathrm{a}} \mathrm{O}_{2}$ in CSA and $0.5 \mathrm{~L} \cdot \mathrm{min}^{-1} / \%$ fall in $\mathrm{Sa}_{\mathrm{a}} \mathrm{O}_{2}$ in OSA), values in the middle of a spectrum which, for normal males, is quite wide $[20,21]$. However, there was a difference of $0.8 \mathrm{kPa}$ in the $P$ ET, $\mathrm{CO}_{2}$ at which the patients were tested. The lower $\mathrm{CO}_{2}$ tension of the patients with CSA is likely to have reduced the group's hypoxic responsiveness, possibly obscuring a relatively increased hypoxic sensitivity.

The findings in the present study differ from those of ANDREAS et al. [10], who reported normal hypercapnic ventilatory responses in a group of patients with periodic respiration during sleep and heart failure. In their paper, only nine of the 20 patients studied had central apnoea, with a further 11 patients having hypopnoeas only during sleep, indicating that the group had substantially milder sleepdisordered breathing than the patients in the present study. ANDREAS et al. [10] did demonstrate that, although the group's mean HCVR value was within their normal range, there was a positive relationship between the deg-ree of periodic respiration in sleep and the awake HCVR.

One criticism of the present study might be that, by not including a matched control group, the comparison between HCVR in subjects with OSA and CSA may have been confounded. There is conflicting evidence in the literature regarding the effect of OSA on the HCVR. Previously, in this laboratory, BERTHON-JONES and SulLIVAN [17] examined the HCVR in 13 normal subjects, mea- suring a mean HCVR of $0.34 \pm 0.10 \mathrm{~L} \cdot \mathrm{min}^{-1} \cdot \mathrm{kPa} \mathrm{PCO}_{2}^{-1}$ in that group; later the same authors [22] reported a mean slope of $0.37 \pm 0.05 \mathrm{~L} \cdot \mathrm{min}^{-1} \cdot \mathrm{kPa} \mathrm{PCO}_{2}{ }^{-1}$ in a group of nine normocapnic subjects with OSA, but significantly lower responses in a group of 10 hypercapnic OSA patients (mean slope $0.21 \pm 0.05 \mathrm{~L} \cdot \mathrm{min}^{-1} \cdot \mathrm{kPa} P \mathrm{CO}_{2}^{-1}$ ). In contrast, GoLD et al. [23] reported HCVR to be reduced in pati- ents with OSA. In the latter study, 32 nonhypercapnic patients with sleep apnoea were compared to 17 weight-matched, nonapnoeic control subjects; the nonapnoeic control group were found to have a significantly higher HCVR 
$\left(0.43 \pm 0.29 \mathrm{~L} \cdot \mathrm{min}^{-1} \cdot \mathrm{kPa} P \mathrm{CO}_{2}^{-1}\right)$ than the normocapnic OSA group $\left(0.29 \pm 0.18 \mathrm{~L} \cdot \mathrm{min}^{-1} \cdot \mathrm{kPa} \mathrm{PCO}_{2}{ }^{-1}\right)$. The result measured in the OSA group in the present study is comparable to that reported by GoLD et al. [23] and within the normal range for our laboratory. Because the primary aim of this study was to consider the pathophysiological mechanisms in patients with severe left ventricular failure and either OSA or CSA, we therefore confined our attention to these two groups.

Despite the relative lack of clinical experimental studies of ventilatory control, in the theoretical modelling study of Kноо et al. [24], the likelihood of sustained nonapnoeic respiratory oscillations during sleep increased with increasing ventilatory responsiveness to $\mathrm{PCO}_{2}$. This suggested an important role for high $\mathrm{CO}_{2}$ sensitivity in promoting unstable respiratory control in patients with sleep-disordered breathing. At the other extreme, in the case of low chemoreceptor drive, rapid changes between wakefulness and sleep, accompanied by large fluctuations in blood gas values, also promoted unstable respiration, primarily as a result of changes in respiratory control associated with changes in the sleep-wakefulness state. Between these two extremes, complex patterns of breathing (a balance between chemoreflex-mediated and state-change oscillations) were described. The addition of upper airway loading or occlusion further promoted the possibility of instability.

Fragmented, unstable sleep will promote respiratory instability by a variety of mechanisms. NREM sleep is normally associated with an increase in arterial carbon dioxide tension $\left(\mathrm{Pa}_{\mathrm{a}} \mathrm{CO}_{2}\right)$ of $0.4-0.9 \mathrm{kPa}$ [25]. If sleep onset occurs rapidly, $\mathrm{Pa}, \mathrm{CO}_{2}$ values will be relatively low for that stage of sleep and, hence, promote hypoventilation and/or apnoea [6]. Termination of apnoea by arousal will lead to an abrupt increase in ventilatory drive causing hyperpnoea, which, if followed by sleep onset, is more likely to be associated with apnoea. Periodic breathing at sleep onset is commonly reported as a transient occurrence in normal subjects [25]. This tendency to respiratory instability is likely to be further amplified by sleep fragmentation and/or heightened respiratory chemosensitivity.

The influence of sleep stage on sleep-disordered breathing in heart failure also favours an important role for chemosensitivity. In normal subjects, ventilatory responses both to hypoxia and hypercapnia are reduced in REM sleep compared to NREM [13, 19]. It is commonly reported that central apnoeas in heart failure occur predominantly in stage I and stage II NREM sleep [26]. One explanation for this observation is that the normal reduction of ventilatory responsiveness in REM sleep promotes respiratory stability. Central apnoeas induced by chemoreflex variations will, thus, be less likely to occur during REM sleep.

The findings in the present study suggest that circulatory delay is not as crucial as increased central chemosensitivity in causing central apnoeas during sleep in heart failure. Although the severity of LVD differed between patients with CSA and OSA (mean LVEF of $23 \%$ compared to $29 \%$; $\mathrm{p}<0.05$ ), both patient groups had moderately impaired function. This relatively modest difference in degree of cardiac dysfunction does not appear to explain the difference in apnoea type observed. GuYTon et al. [27] showed that increased heart to brain circulation time, produced by artificially lengthening the carotid arte-ries in dogs, could produce central apnoeas, but the magnitude of the increase (2-5 min) was considerably longer than seen in patients with heart failure. NAUGHTON et al. [8] provided indirect evidence of a link between apnoea/hypopnoea cycle length and lung ear circulation time, estimated from the ear oximeter, but not the presence or absence of CSA. Therefore, prolonged circulation time associated with heart failure appears to affect mainly the periodicity rather than presence or absence of central ap-noeas.

Hypoxia is an important amplifier of unstable respiratory control. In normal subjects at altitude, hypoxia is the primary stimulus to hyperventilation, which causes hypocapnia and central apnoea [28]. Eucapnic hypoxia is not associated with periodic respiration. This primary role for hypoxia is confirmed by the elimination of unstable respiration with supplemental oxygen [29]. In contrast, oxygen is reported to reduce (by approximately 50\%), but not abolish, central apnoeas in heart failure, suggesting that, while hypoxia amplifies unstable respiratory control in heart failure [30], it is not the main factor responsible for central apnoea. The relatively normal responses to eucapnic hypoxia found in patients with CSA may be important, since it is likely that relatively low hypoxic responsiveness may tend to "protect" patients with heart failure from developing central apnoea during sleep. Our results, however, cannot provide a clear answer to this question as the tests were performed at a much lower background $\mathrm{CO}_{2}$. Importantly, while the patients with CSA reported in this study had normal resting $\mathrm{Sa}_{\mathrm{a}} \mathrm{O}_{2}$ values during wakefulness (which did not differ significantly from the values obtained in the OSA group (see table 1)), significant repetitive hypoxaemia occurred during sleep, undoubtedly contributing to respiratory instability.

Relatively few females have been included in studies of patients with sleep-disordered breathing and heart failure. The prevalence of obstructive sleep apnoea in females has been examined systematically in a number of studies [31, 32], and shown to be approximately half as common as it is in males. The influence of gender on the prevalence of CSA has not been examined methodically but, despite not specifically excluding females, only one of the patients in this study was female. Similar findings have been reported by other investigators $[1-3,8,30]$. This apparent gender difference may be at least partly explained by the influence of ventilatory responses, since both eucapnic hypoxic and hyperoxic hypercapnic ventilatory responses are significantly lower in females compared to males [21, 33].

The difference in age and weight between those patients with CSA and those with OSA would not explain the observed differences in ventilatory responsiveness. In normal subjects, there is a positive correlation between weight and hypercapnic responsiveness [20], but in the present study patients with CSA, who were significantly lighter, had significantly increased HCVRs. Ageing tends to reduce ventilatory responsiveness both to hypoxia and hypercapnia [34]. Although the patients with CSA were older than the patients with OSA (mean age 65 yrs compared to $55 \mathrm{yrs} ; \mathrm{p}<0.001$ ), both groups of patients were middle-aged, and the absolute difference in their ages were considerably less than in published reports showing an effect of age on ventilatory responsiveness.

There are several potential mechanisms which may have been responsible for the increased HCVRs observed in patients with CSA. One possibility is that many of the 
patients may have had high-normal responses prior to the development of sleep-disordered breathing and were, therefore, susceptible to developing pathologically increased responses due to the interaction of other factors, such as hypoxia and pulmonary congestion. Although the degree of LVD (as estimated by the resting LVEF) did not differ markedly between patients with CSA and OSA, this does not exclude the possibility that there were important differences in haemodynamic variables, such as the pulmonary capillary wedge pressure. It is also likely that there are important interactions between these factors. For example, patients with CSA and high-normal responses prior to developing heart failure may develop an additional and pathological increase in hypercapnic drive in response to increased pulmonary afferent nerve activity.

Hypocapnia observed during wakefulness in subjects with heart failure is clearly linked with unstable respiration during sleep in some of these patients. The observation of increased ventilatory responsiveness to $\mathrm{CO}_{2}$ shown in patients with LVD and CSA in the present study suggests that hypocapnia at rest is due, at least partly, to an upward resetting of ventilatory responses to $\mathrm{CO}_{2}$. Since the effects of hypoxia and hypercapnia on ventilation are normally synergistic, hyperoxia, which inhibits carotid body chemoreceptors, may reduce respiratory instability during sleep in heart failure by reducing the amplifying effect of peripheral chemoreceptor activity on central respiratory control, thus providing a rational basis for the use of supplemental oxygen during sleep in patients with heart failure. Furthermore, drugs, such as opiates and benzodiazepines, which are respiratory depressants, may not only be less likely to have this effect in patients with heart failure, but may have a therapeutic role by reducing the severity of sleep-disordered breathing in CSA associated with heart failure.

Thus, the present findings taken together with previously published data suggest that central chemoreceptor sensitivity may be an important factor influencing the type of apnoea seen in patients with heart failure and sleep-disordered breathing. Increased hypercapnic ventilatory responsiveness, potentially due to a number of factors (e.g. genetic, pulmonary venous congestion, hypoxia), will promote the development of periodic respiration during wakefulness and central apnoeas during sleep, when combined with the increased circulation time that results from the onset of left ventricular dysfunction. The various factors which influence the presence and severity of central sleep apnoea are likely to vary markedly between individual patients. Although we have shown that, as a group, hypercapnic ventilatory response is increased in patients with central sleep apnoea, a wide range of responses was seen, and it is likely that the hypercapnic ventilatory response is a relatively more important factor in those patients with the highest hypercapnic ventilatory responses.

Acknowledgements: The authors thank M. Baric and the nursing staff of the Centre for Respiratory Failure and Sleep Disorders for their help during this study. T-S. Yang assisted with scoring of polysomnographic recordings. The authors thank K.C. Allman, G. Bautovich and A.F. McLaughlin of the Department of Nuclear Medicine, Royal Prince Alfred Hospital, for reporting the gated blood pool scans.

\section{References}

1. Cheyne J. A case of apoplexy, in which the fleshy part of the heart was converted into fat. Dublin Hospital Reports 1818; 2 : 216-223.

2. Stokes W. The diseases of the heart and aorta. Dublin, Hodges and Smith, 1854; pp. 302-337.

3. Harrison TR, King CE, Calhoun JA, Harrison WG. Congestive heart failure: Cheyne-Stokes respiration as the cause of paroxysmal dyspnoea at the onset of sleep. Arch Intern Med 1934; 53: 891-910.

4. Prior WW. Cheyne-Stokes respiration in patients with cardiac enlargement and prolonged circulation time. Circulation 1951; 4: 223-238.

5. Sullivan C, Kozar L, Murphy E, Phillipson E. Primary role of respiratory afferents in sustaining breathing rhythm. J Appl Physiol 1974; 37: 353-356.

6. Skatrud JB, Dempsey JA. Interaction of sleep state and chemical stimuli in sustaining rhythmic ventilation. $J$ Appl Physiol: Respirat Environ Exercise Physiol 1983; 55: 813-822.

7. Bradley D, McNicholas WT, Rutherford R, Popkin J, Zamel N, Phillipson EA. Clinical and physiologic heterogeneity of the central sleep apnoea syndrome. Am Rev Respir Dis 1986; 134: 217-221.

8. Naughton M, Benard D, Tam A, Rutherford R, Bradley TD. Role of hyperventilation in the pathogenesis of central sleep apneas in patients with congestive heart failure. Am Rev Respir Dis 1993; 148: 330-338.

9. Wilcox I, Grunstein RR, Berthon-Jones M, Collins FL, Kelly DT, Sullivan CE. Role of central chemosensitivity in central sleep apnoea associated with heart failure. Sleep 1993; 16: S37-S39.

10. Andreas S, von Breska B, Kopp E, Figulla HR, Kreuzer H. Periodic respiration in patients with heart failure. Clin Invest 1993; 71: 281-285.

11. Chua TP, Clark AL, Amadi AA, Coats AJS. Relation between chemosensitivity and the ventilatory response to exercise in chronic heart failure. J Am Coll Cardiol 1996; 27: 650-657.

12. Rechtschaffen A, Kales A, eds. A manual of standardized terminology. Techniques and scoring systems for sleep stages of normal subjects. Bethesda, National Institutes of Health, Publication No. 204, 1968.

13. Berthon-Jones M, Sullivan CE. Ventilatory and arousal responses to hypercapnia in normal sleeping humans. $J$ Appl Physiol: Respirat Environ Exercise Physiol 1984; 57: 59-67.

14. Read DJC. A clinical method for assessing the ventilatory response to carbon dioxide. Aust Ann Med 1966; 16 : 20-32.

15. Rebuck AS, Campbell EJM. A clinical method for assessing the ventilatory response to hypoxia. Am Rev Respir Dis 1973; 109: 345-350.

16. Javaheri S, Parker TJ, Wexler L, et al. Occult sleep-disordered breathing in stable congestive heart failure. Ann Intern Med 1995; 122: 487-492.

17. Berthon-Jones M, Sullivan CE. Ventilation and arousal responses to hypercapnia in normal sleeping humans. $J$ Appl Physiol: Respirat Environ Exercise Physiol 1984; 57: 59-67.

18. Malone S, Lui P, Holloway R, Xie A, Bradley TD. Obstructive sleep apnoea in patients with dilated cardiomyopathy: effects of continuous positive airway pressure. Lancet 1991; 338: 1480-1484. 
19. Hirshman CA, McCulloch RE, Weill JV. Normal values for hypoxic and hypercapnic ventilatory drives in man. $J$ Appl Physiol 1975; 38: 1095-1098.

20. Berthon-Jones M, Sullivan CE. Ventilatory and arousal responses to hypoxia in sleeping man. Am Rev Respir Dis 1982; 125: 632-639.

21. McCauley VB, Grunstein RR, Sullivan CE. Ethanolinduced depression of hypoxic drive and reversal by naloxone - a sex difference. Am Rev Respir Dis 1988; 137: 1406-1410.

22. Berthon-Jones M, Sullivan CE. Time course of change in ventilatory response to $\mathrm{CO}_{2}$ with long-term CPAP therapy for obstructive sleep apnea. Am Rev Respir Dis 1987; 57: 144-147.

23. Gold AR, Schwartz AR, Wise RA, Smith PL. Pulmonary function and respiratory chemosensitivity in moderately obese patients with sleep apnea. Chest 1993; 103: 13251329.

24. Khoo MCK, Gottschalk A, Pack AI. Sleep-induced periodic breathing and apnoea: a theoretical study. J Appl Physiol 1991; 70: 2014-2024.

25. Krieger J. Breathing during sleep in normal subjects. In: Kryger MH, Roth T, Dement W, eds. Principles and Practice of Sleep Medicine. 2nd edn. Philadelphia, W.B. Saunders, 1994; pp. 212-223.

26. Hanly PJ, Millar PW, Steljes PG, Baert R, Frais MA, Kryger MH. Respiration and abnormal sleep in patients with congestive heart failure. Chest 1989; 96: 480-488.

27. Guyton AC, Crowell JH, Moore JW. Basic oscillating mechanism of Cheyne-Stokes breathing. Am J Physiol 1956; 187: 385-398.

28. Reite M, Jackson D, Cahoon RL, Weill JV. Sleep physiology at high altitude. Electroencephalogr Clin Neurophysiol 1975; 38: 463-471.

29. Berssenbrugge A, Dempsey J, Iber C, Skatrud J, Wilson P. Mechanisms of hypoxia-induced periodic breathing during sleep in humans. J Appl Physiol 1983; 343: 507524.

30. Hanly PJ, Millar TW, Steljes DG, Baert R, Frais MA, Kryger MH. The effect of oxygen on respiration and sleep in patients with congestive heart failure. Ann Intern Med 1989; 111: 777-782.

31. Young T, Palta M, Dempsey J, Skatrud J, Weber S, Badr $\mathrm{S}$. The occurrence of sleep-disordered breathing among middle-aged adults. N Engl J Med 1993; 328: 1250-1253.

32. Bearpark H, Elliot L, Grunstein R, et al. Occurrence and correlates of sleep-disordered breathing in the Australian town of Bussleton: a preliminary analysis. Sleep 1993; 16: S3-S5.

33. White DP, Douglas NJ, Pickett CK, Weill JV, Zwillich CW. Sexual influence on the control of breathing. J Appl Physiol: Respirat Environ Exercise Physiol 1983; 54: 874-879.

34. Peterson DD, Pack AI, Silage DA, Fishman AP. Effects of aging on ventilatory and occlusion pressure responses to hypoxia and hypercapnia. Am Rev Respir Dis 1981; 124: 387-391. 